\title{
Economia feminista: metodologias, problemas de pesquisa e propostas teóricas em prol da igualdade de gêneros
}

\author{
Feminist economics: methodologies, research problems \\ and theoretical proposals toward gender equality
}

BRENA PAULA MAGNO FERNANDEZ*

\begin{abstract}
RESUMO: Em que pesem as conquistas observadas nas últimas décadas tanto em termos de direitos políticos quanto da crescente participação das mulheres no mercado de trabalho, desigualdades de gênero ainda persistem em vários aspectos da vida social, sendo o econômico talvez um dos mais visíveis deles. Fenômenos como as diferenças salariais entre homens e mulheres que desempenham idênticas funções, a segregação sexual no mercado de trabalho, a inserção feminina em trabalhos mais precários, bem como a sobrecarga nos trabalhos domésticos são alguns dos objetos de investigação da chamada economia feminista. Partindo desta perspectiva crítica e contrapondo-a com a perspectiva-padrão em economia, o presente artigo propõe-se a mapear algumas propostas teóricas e instrumentos metodológicos disponíveis para identificar estas desigualdades de gênero. Além disso, apontamos a necessidade de rever os preceitos e conceitos da economia ortodoxa à luz das críticas da economia feminista e do princípio da igualdade de gênero, considerando as esferas produtiva e reprodutiva e as relações existentes entre elas.

PALAVRAS-CHAVE: Economia Feminista; (Des)igualdade de Gênero; Metodologia Feminista; Gênero e Economia.
\end{abstract}

ABSTRACT: In spite of the achievements observed in recent decades both in terms of political rights and the increasing participation of women in the labor market, gender inequalities still persist in various aspects of social life, being the economic perhaps one of the most visible one. We could list phenomena such as the wage gap between men and women who perform identical functions, sex segregation in the labor market, women's insertion in more precarious jobs and the burden of domestic work as some of the main research objects of the so called feminist economics. Confronting this critical approach with the mainstream

* Universidade Federal de Santa Catarina-UFSC, Brasil. E-mail: brenafernandez@hotmail.com. Submetido: 13/Março/2017; Aprovado: 6/Outubro/2017. 
economics, this article aims to map some theoretical proposals and methodological tools available to identify gender inequalities. We also point out the need to review some principles and concepts of orthodox economics in the light of the criticism of feminist economics and the perspective of gender equality, considering the productive and reproductive spheres and the relations between them.

KEYWORDS: Feminist Economics; Feminist Methodology; Gender (In)equality; Gender and Economics.

JEL Classification: B41.

\section{INTRODUÇÃO}

O que chamamos de economia feminista, no singular, dificilmente pode exprimir a polifonia que melhor caracteriza essa área de investigação. Economistas feministas provêm originalmente de diferentes escolas da economia, a começar pela neoclássica, passando pela institucionalista, pós-keynesiana, social e ecológica, chegando até a marxista. Simultaneamente, vinculam-se ainda a distintas vertentes políticas do movimento feminista (liberal, radical, marxista, por exemplo). Essa diversidade de origens teóricas de base, bem como de inclinações políticas reflete-se, obviamente, na escolha das abordagens metodológicas que cada autor/a privilegiará. Por esse motivo, não é casual que tanto os seus objetivos teóricos quanto as suas estratégias de pesquisa sejam, da mesma forma, extremamente variados e as suas conclusões, por vezes, conflitantes. Por uma questão de delimitação de escopo, no artigo optamos por não entrar nessa discussão, deixando o problema aqui apenas assinalado. Não obstante, e a despeito de todas as divergências internas dessa multiplicidade de vozes, o mínimo denominador comum que permite o tratamento da economia feminista como um todo estruturado é a introdução do gênero como categoria analítica também na economia.

A economia tradicional não contempla em seu objeto de estudo a perspectiva de gênero, vale dizer, a possibilidade de que, no espaço econômico, o tratamento dado a homens e mulheres possa ser diferente (e, no caso, discriminatório para com as mulheres) como consequência dos distintos papéis sociais que historicamente têm desempenhado. Tampouco aborda a produção doméstica e a troca de valores de uso. Por definição, apenas se consideram como pertencentes ao âmbito econômico aqueles bens e serviços que se destinam à transação mercantil, à troca no mercado, e aos quais por isso mesmo foi atribuído um preço de mercado. Todo tipo de atividade transformadora tradicionalmente realizada por mulheres, ou seja, todos os bens e serviços que são produzidos, realizados e consumidos dentro do espaço familiar, e pelos quais não seja cobrada uma contrapartida financeira, precisamente por este motivo permanecem fora do foco de interesse da economia tradicional. Neste sentido, a perspectiva da economia feminista direciona uma crítica que propõe um olhar estranho à tradição econômica desde o estabelecimento da economia como disciplina científica autônoma no século XVIII.

Historicamente, foram questões de caráter bem prático aquelas que impulsio- 
naram as primeiras investigações acerca da condição feminina na economia. Estas questões tornaram-se mais visíveis e começaram a chamar mais atenção há relativamente pouco tempo, nos meados do século $\mathrm{XX}^{1}$. A incorporação massiva das mulheres no mercado de trabalho durante os períodos subsequentes às duas grandes guerras mundiais no século passado foi um fenômeno sem precedentes históricos e que deu ensejo a toda uma gama de preocupações que antes, de modo geral, não existiam. $\mathrm{O}$ fato de as mulheres passarem a ocupar postos de trabalho que antes eram desempenhados exclusivamente por homens trouxe para a ordem do dia questões muito variadas, que nunca haviam sido formuladas pela tradição em economia. Perguntas atinentes à possibilidade de participação no espaço público por parte das mulheres, à modalidade dos trabalhos desempenhados por elas, às suas ocupações típicas, às condições de estabilidade ou de intermitência destes trabalhos, aos seus salários, à existência ou não de diferenças entre as pautas laborais masculinas e femininas, à dupla jornada de trabalho, à tentativa de identificação de discriminação contra as mulheres no ambiente de trabalho, bem como aos modos como as diversas discriminações poderiam manifestar-se são algumas das questões pedra de toque para a economia dita feminista.

Além disso, à medida que a mulher se foi incorporando no mercado de trabalho remunerado, tal passou a ter impacto na produção e no trabalho doméstico, não remunerado, que ela realizava tradicionalmente em casa. Surgem aí ainda outras questões que a ciência econômica é chamada a encaminhar: a valorização do trabalho remunerado em face do trabalho não remunerado e a repartição do tempo entre ambos os tipos de atividades são questões que afetam em cheio as mulheres e não tão diretamente os homens, e se afetam, pelo menos não o fazem com a mesma intensidade. Por esse motivo, sob o prisma da economia feminista, é pertinente relacionar ambos os tipos de trabalhos, o público e o privado, o visível e o invisível, o pago e o não pago, investigando quais serão as suas interferências recíprocas. Assim, importa aferir os impactos que as obrigações da mulher em casa e o tempo gasto nos afazeres domésticos e no cuidado com a família têm sobre a sua situação no mercado de trabalho, e vice-versa.

Por outro lado, a despeito dessa compreensível preocupação com várias questões de caráter pragmático, a abordagem da economia feminista não pretende reduzir-se a apontar problemas típicos de pessoas do gênero feminino. Economistas feministas também se envolveram na discussão filosófica sobre os fundamentos epistemológicos e metodológicos da economia em diálogo com as tradições pós-modernas, pós-coloniais, do realismo crítico e outras abordagens, explorado comparações de métodos com várias escolas heterodoxas da economia, nomeadamen-

\footnotetext{
${ }^{1}$ Importa notar, entretanto, que há autores/as (Cf., por exemplo, Carrasco, 2006) que ponderam que existem contribuições àquilo que hoje chamamos de economia feminista que remontam quase que à época do surgimento da economia enquanto disciplina autônoma. Dentre as questões por ela elencadas como relevantes há muito tempo estão: os maiores níveis da pobreza feminina comparativamente à pobreza masculina, a luta pela igualdade de direitos (civis, trabalhistas e salariais), assim como o trabalho doméstico.
} 
te a economia pós-keynesiana (Danby, 2004; Staveren, 2008), a economia institucionalista (Nelson, 2003), a economia social (Emami, 1993) e a economia ecológica (Perkins, 1997).

Como referimos atrás, o que permite o tratamento teórico destas múltiplas influências como uma única corrente de pensamento é a introdução da categoria analítica do gênero também na economia. Hoje em dia, o termo "gênero" é costumeiramente definido na literatura como "o significado social atribuído às diferenças biológicas entre os sexos” (Ferber e Nelson, 1993, p. 9). Muito embora esse conceito tenha variado algo no tempo, ele sempre teve como referência a diferença sexual (distinção entre homem e mulher, macho e fêmea), e do modo como esta diferença permite compreender uma dimensão fundamental sobre como estão estruturadas as relações sociais. É a partir desta concepção do conceito de gênero que a crítica feminista à economia é formulada: características tradicionalmente atribuídas por um lado aos homens e por outro às mulheres como naturais (no sentido de biológicas) são características, em última instância, comuns a toda espécie humana, sendo sua identificação como tipicamente "masculinas" ou "femininas" uma questão muito mais histórica e cultural do que propriamente relativa à natureza.

A predominância e o privilégio de traços, características, atitudes e comportamentos tradicionalmente considerados como tipicamente masculinos (como a razão, o rigor e a objetividade) na moderna cultura ocidental promoveram - de acordo com a visão feminista - uma injusta e deletéria subjugação dos aspectos e características identificados como predominantemente femininos (como a emoção, a flexibilidade e a subjetividade), considerados inferiores e/ou marginais. Neste processo, que é a um tempo violento em suas consequências porém sutil em seus meandros, as mulheres foram paulatinamente subjugadas e a sua capacidade de ação, cerceada.

Como um dos principais objetivos do movimento feminista é o de promover a expansão do exercício da ação (agency) onde esta capacidade foi diminuída ou inexiste, no caso ora em pauta trata-se da expansão do exercício da ação no escopo da economia. Por outras palavras, a expansão da capacidade de ação neste caso representa o empoderamento feminino por intermédio da obtenção de um emprego, do desenvolvimento de uma carreira e de uma vida profissional e, como consequência, a obtenção da independência financeira. A expectativa dos vários enfoques da economia feminista é a de que esta possibilidade dependerá, por um lado, do tratamento teórico destas questões para que, por outro, possa se dar a eliminação política das causas que levaram à restrição da ação feminina, nomeadamente no campo laboral. Assim, expandir o exercício da ação torna-se um ponto fulcral tanto do movimento político do feminismo, quanto do projeto teórico da economia feminista.

No contexto teórico do feminismo, revelar o gênero significa trazer à luz uma relação assimétrica de poder que tem estado relativamente oculta e que suprime a atividade autônoma das mulheres enquanto assalariadas e/ou profissionais ou mesmo enquanto empresárias. Essa relação assimétrica é sustentada seja por instituições sociais, seja por práticas simbólicas arraigadas. É por meio da naturalização das diferenças de gênero nos modelos tradicionais das ciências da vida, das corren- 
tes convencionais na economia e demais ciências sociais, que as relações de poder e a assimetria entre gêneros daí decorrentes tornam-se invisíveis.

No âmbito socioeconômico, é precisamente a esta tarefa que se dedica a economia feminista: revelar os efeitos perversos dessa assimetria entre gêneros. Essa assimetria e poder pode ser constatada tanto na falta de igualdade de oportunidades no mercado de trabalho como na defasagem dos ganhos econômicos que podem ser obtidos pelas mulheres, quando comparados com aqueles auferidos pelos indivíduos do gênero masculino com idêntica formação e que exercem idêntica função.

Em primeiro lugar, pesquisadores/as da economia feminista pretendem repensar vários conceitos e categorias - enviesados, segundo creem -, com os quais se define, se mede e se estuda a economia, colocando em questão a suposta objetividade que o modelo tradicional reclama possuir. Sob o prisma teórico-metodológico, a economia feminista se propõe a desenvolver novas perspectivas e novas formas de ver o mundo social e econômico que permitam tornar visível o que tradicionalmente a disciplina tem mantido como oculto.

Partindo-se desta introdução à questão, necessariamente bastante esquemática e breve, pretende-se neste artigo expor algumas das propostas teóricas e dos instrumentos metodológicos a partir da perspectiva da economia feminista, no sentido de mapear este cenário de desigualdades de gênero. Um desdobramento sempre desejável é o de que os resultados obtidos neste tipo de estudos possam servir de subsídio para o desenvolvimento de políticas públicas que, a um tempo, caracterizem um papel mais propositivo por parte do Estado e estimulem o processo de transformação das convenções sociais de gênero na direção de uma sociedade mais emancipada e igualitária.

Em termos específicos, o artigo tem por finalidade identificar o que constitui o programa de pesquisa em economia feminista, detalhando qual o escopo de sua pesquisa, e definindo quais são suas características metodológico-epistemológicas distintivas em relação a outros programas de pesquisa ortodoxos em economia. À luz da economia feminista, pretende-se apontar por que, apesar da crescente participação das mulheres no mercado do trabalho e de suas conquistas em termos de direitos reprodutivos, sociais, políticos, até o presente momento ainda persistem traços discriminatórios como diferenças salariais entre homens e mulheres para idênticas funções, segregação ocupacional ou inserção feminina em trabalhos mais precários. Como embasamento empírico, apresentamos o resultado de um estudo recente (com dados da Pnad de 2004 a 2014) realizado pelo Instituto Brasileiro de Geografia e Estatística (IBGE) e elaborado pelo Instituto de Pesquisas Econômica Aplicada (IPEA, 2016) que corrobora o diagnóstico de subjugação das mulheres no cenário laboral brasileiro. Pelas razões teóricas apresentadas ao longo do texto, respaldadas pelo resultado empírico para o caso brasileiro, apontamos para a necessidade de revisão dos preceitos e conceitos da economia ortodoxa à luz das críticas da economia feminista e do princípio da igualdade de gênero, considerando as esferas produtiva e reprodutiva e as inter-relações existentes entre elas.

Em relação à estrutura e organização do artigo, assim como à apresentação 
das diversas seções, ele foi, em boa medida (porém não exaustivamente) ${ }^{2}$, construído a partir dos eixos temáticos indicados nas últimas páginas do texto, como anexo. Trata-se de um tutorial (Syllabus), onde são apresentadas algumas das principais linhas de investigação colocadas em marcha pela economia feminista, bem como uma sugestão de referências bibliográficas com elas relacionadas. Identificamos ali sete linhas de pesquisa representativas e atuais da economia feminista e, em cada uma delas, apontamos alguns artigos, livros e coletâneas que possam servir de guia para o leitor ainda não familiarizado com a área da economia feminista, porém interessado nos respectivos assuntos, quais sejam:

I. Gênero e Economia: Aspectos filosóficos e metodológicos:

II. Economia feminista: enfoques, conceitos e propostas teóricas;

III. Trabalho doméstico não remunerado/trabalho não pago/trabalho invisível;

IV. Gênero e desigualdade de salários;

V. Gênero e segregação/discriminação no mercado de trabalho;

VI. Gênero, políticas macroeconômicas voltadas para o desenvolvimento, e o neoliberalismo; e finalmente,

VII. Economia feminista e suas interseções com outras abordagens heterodoxas.

Sem qualquer pretensão de exaurir o tema com esta lista de indicações, seja quanto aos sete eixos temáticos propostos, seja no que concerne as referências bibliográficas sugeridas no Syllabus ${ }^{3}$, partimos de tópicos mais gerais, filosóficos e teóricos, passando por discussões mais pontuais em diferentes temas referentes à interseção entre gênero e economia, enfatizando sempre as questões que compõem um território comum das abordagens teóricas ditas heterodoxas. Trata-se sobretudo, como dito, de oferecer uma imagem de conjunto, uma sugestão de enquadramento conceitual que funcione como mapa ou guia das possíveis linhas de pesquisa em curso no contexto da economia feminista ${ }^{4}$.

\section{GÊNERO E ECONOMIA: ASPECTOS FILOSÓFICOS E METODOLÓGICOS}

Em grande medida, como já é bem conhecido, os estudos de gênero são legatários dos movimentos feministas das décadas de 1960 e 1970. Para além das preocupações sociais e políticas que deram ensejo ao movimento, estes estudos

\footnotetext{
${ }^{2}$ Por se tratar de um assunto tangente e com muitas interconecções com os demais, optamos por abordar as questões atinentes ao eixo VII - Economia feminista e suas interseções com outras abordagens heterodoxas - em diversos momentos do texto e não como uma seção em separado.

${ }^{3}$ Ainda em relação à bibliografia sugerida no Syllabus, certamente que ela inspirou a redação das seções temáticas do artigo, muito embora não tenha sido explicitamente utilizada na redação. As obras que foram mais diretamente usadas em cada seção encontram-se referidas ao longo do texto.

${ }^{4}$ Por uma questão de limitação de páginas do artigo, optamos por indicar apenas cinco obras de referência para cada um dos sete eixos temáticos sugeridos no Syllabus. Artigos mais recentes, bem como textos cujo foco seja algum outro assunto na interseção entre gênero e economia, podem ser encontrados naquele que já é o periódico de referência da área: a revista Feminist Economics.
} 
voltaram-se posteriormente para as questões filosóficas, metodológicas e epistemológicas relacionadas, bem como para as construções teóricas propriamente ditas. $\mathrm{O}$ gênero passou a ser entendido como uma categoria-chave para a compreensão de como e por que, em diversas sociedades e conjunturas históricas, os indivíduos, grupos e instituições atribuem determinados significados àquilo que deva ser propriamente associado ao masculino e ao feminino.

Os estudos de gênero pretendem então, por um lado, descrever, interpretar, problematizar, analisar e explicar as configurações institucionais que determinam aquilo que é considerado legítimo, os papéis sociais dados como adequados para os homens e as mulheres, e respectivos valores, códigos de conduta, práticas e normas. Por outro lado, busca-se desvelar as relações de poder que vêm sendo historicamente estabelecidas, que se exprimem nos processos de dominação dos indivíduos do gênero masculino sobre os do gênero feminino a partir destas configurações de conduta.

De acordo com este enquadramento crítico e tomando como parâmetro a questão que nos interessa mais diretamente aqui, identifica-se que a escassa e precária participação das mulheres, quer nos diversos setores da economia, quer na própria academia, na ciência econômica, denota os preconceitos de uma sociedade que combina diferentes tipos de discriminação - sociais, culturais, econômicas, raciais e de gênero. Ademais, a economia feminista também aponta que alguns dos parâmetros mais caros ao conhecimento científico, como a racionalidade, a objetividade, a abstração e a universalidade estariam deformados por valorações androcêntricas e sexistas, em suma, depreciativas do sexo feminino.

Os desdobramentos metodológicos da crítica feminista colocam em xeque determinados conceitos e enfoques científicos por refletirem vieses androcêntricos. Porém, a sua crítica de maior peso é a de que a suposta universalidade que os resultados obtidos pela ciência moderna reclama possuir é falsa, uma vez que estes resultados manifestam apenas fracamente os valores de domínios relevantes de fenômenos. Além disso, as pesquisas científicas conduzidas a partir do método tradicional ignoram (e/ou não permitem o desenvolvimento de) abordagens mais promissoras no que diz respeito às questões da desigualdade de gêneros. As abordagens científicas - métodos e teorias - alternativas propostas pela economia feminista seriam justamente aquelas que incorporam outros valores, códigos culturais de conduta, práticas e normas tradicionalmente associados às mulheres, os quais vêm sendo subjugados, marginalizados e/ou cerceados.

Muitas/os economistas feministas argumentam que o formalismo e a modelagem da teoria da escolha econômica tradicional, bem como o foco nos métodos matemáticos e econométricos que o mainstream da economia historicamente tem privilegiado representam uma cama de Procusto. Isto porque este instrumental não conseguiria captar toda uma rede de conexões entre a economia e outros fenômenos sociais fronteiriços à economia, sejam eles políticos, históricos, sociais ou psicológicos, bem como as relações de dominação que se estabeleceram dentro do âmbito da economia. O uso de estudos históricos, estudos de caso, entrevistas e outras abordagens qualitativas, assim como uma maior atenção a questões como 
a qualidade dos dados e a replicação dos trabalhos de cariz quantitativo estão sendo explorados (Bergmann, 1989; Nelson, 1995). Os teóricos da economia feminista tendem a acreditar que tais esforços possam criar e promover formas mais adequadas de pesquisa em economia, conduzindo a novos insights, independentemente de se relacionarem ou não com as questões de gênero.

Diretamente vinculadas à questão do uso exclusivo de um determinado conjunto de ferramentas metodológicas estão as dúvidas levantadas acerca da própria definição de economia, do seu ponto de partida, da sua imagem central focada no "homem econômico". Assim, outra crítica importante que se faz à corrente dominante na economia, à teoria neoclássica, refere-se ao caráter androcêntrico expresso já de partida no seu conceito basilar - o homo oeconomicus, agente econômico autônomo, com preferências estáveis ao longo do tempo, racional e maximizador da utilidade esperada. De uma forma muito simplificada e crua, maximizar a utilidade esperada norteando-se pela busca do interesse próprio é o que se entende como a expressão da racionalidade do agente econômico.

Segundo a crítica feminista, tal entidade abstrata não conseguiria capturar toda uma gama de comportamentos humanos também possíveis (e existentes no mundo factual), norteados por outros princípios que não a busca da maximização do interesse próprio, tais como o senso ético, a disposição para cooperar, algum sentido de obrigatoriedade para com os demais indivíduos da sociedade, enfim, alguma possibilidade de comportamento em benefício de outrem. O homo oeconomicus é o protótipo de um indivíduo do gênero masculino, adulto, que não precisa cuidar das obrigações da casa, criar filhos, cuidar dos enfermos da família e nem dos pais idosos. Nesse sentido, o homem econômico, por um lado, não pode representar $50 \%$ da humanidade composta por homens. Tampouco representa adequadamente o comportamento dos restantes $50 \%$ composto por mulheres. De fato, tomando-se como parâmetro esta ótica conceitual, um número expressivo de mulheres não pode se enquadrar na "normalidade" que é assumida pela teoria, pois social e culturalmente (ainda) estão muitíssimo associadas não ao trabalho extradoméstico, que produz riqueza e gera bens e serviços para a troca mercantil (este sim vinculado ao comportamento tipicamente representado pelo homem econômico), mas antes às relações sociais, às suas relações familiares, aos cuidados da família e da casa.

Sendo assim, tomando-se o homem econômico como hipótese central das teorias mainstream da economia, as investigações realizadas a partir da perspectiva tradicional são conduzidas desde um determinado conjunto de valores culturais, sociais, profissionais, enfatizando características que se entende serem masculinas. Para além do egoísmo e da racionalidade maximizadora da utilidade do bomo oeconomicus, os próprios modelos expressam valores também de natureza androcêntrica, nomeadamente a autonomia, a separação e a abstração. Historicamente, estes valores culturalmente identificados como masculinos adquiriram precedência sobre os valores considerados tipicamente femininos, como a interdependência, a conexão e a concretude. Por esta razão, ao invés de representar o rigor na disciplina, a exclusividade do método formal promovida pela incorporação deste viés teria 
antes enfraquecido a capacidade da economia de explicar os fenômenos do mundo real. As questões metodológicas levantadas contra a economia ortodoxa dizem respeito justamente ao fato de ela, dados os vieses axiológicos a que está sujeita, não ser suficientemente objetiva.

Por todos os motivos atrás elencados, no plano metodológico a estratégia feminista pressupõe a priorização de algumas formas alternativas de compreensão dos fenômenos sociais. Ela encoraja, por exemplo, a pesquisa baseada em modelos de comportamento divergentes do modelo tradicional, no sentido de que sejam suficientemente complexos de modo a refletir a intencionalidade da ação (em substituição à racionalidade da ação, como acabamos de referir). Essas suposições tendem a direcionar as teorias rumo à "complexidade, à heterogeneidade ontológica, à interação e, consequentemente, ao não reducionismo" (Lacey, 1999, p. 208).

A crítica ao caráter masculinista não só veio a por a nu a pretensa universalidade do pensamento econômico tradicional, como também permitiu desembocar na reivindicação de uma abordagem multidisciplinar para a economia, em que as interpretações econômicas fossem enriquecidas pelos aportes de outras disciplinas, nomeadamente a sociologia, a antropologia, a ciência política, a psicologia social e a história. Este é um exemplo típico de reivindicação compartilhada tanto pela economia feminista quanto pelas demais correntes heterodoxas em economia, como a economia pós-keynesiana, a economia social, a corrente institucionalista e a ecológica.

De fato, as críticas feministas ao arcabouço metodológico do mainstream da Economia são convergentes com um tipo de questionamento que já vem sendo feito há algum tempo por outras abordagens heterodoxas não feministas. Acreditamos que este fato possa contar como um ponto a favor das reivindicações feministas, e não contra elas. Se uma crítica pode ser defensável a partir de diferentes perspectivas teóricas, isso deveria denotar a robustez de suas demandas comuns, mais do que uma eventual fraqueza decorrente de algumas outras divergências ou de particularidades de cada eixo teórico que necessitam ainda ser discutidas. Nesse sentido, é bastante oportuna uma observação de Julie Nelson (1995, p. 146), uma das economistas feministas mais atuantes desde a década de 1990: "Vários leitores podem ter descoberto que já estão fazendo 'economia feminista' de alguma forma, muito embora prefiram pensar em si mesmos como fazendo apenas 'boa economia'”. O ponto para o qual essa observação chama a atenção ficará mais claro nas seções seguintes, onde as semelhanças entre a perspectiva metodológica da economia feminista e das demais abordagens heterodoxas em economia serão mencionadas.

\section{ECONOMIA FEMINISTA: ENFOQUES, CONCEITOS E PROPOSTAS TEÓRICAS}

Numa primeira leitura, bastante ampla, as/os economistas feministas acreditam que, em termos tanto metodológicos quanto de problemas e objetivos de pesquisa, a economia trata de um mundo de homens. E isso não apenas porque as mulheres estão sub-representadas na ciência: em 2014 as mulheres constituíam apenas 12\% 
dos professores de economia norte-americanos, e até à data há apenas uma vencedora mulher do Prêmio Nobel em Ciências Econômicas ${ }^{5}$ (Nelson, 1995). Mas também, e talvez o fator mais importante, para além de não elaborar nem conseguir endereçar algumas das perguntas fundamentais relativas à condição feminina no contexto econômico, a teoria econômica tradicional tem cimentado a desigualdade de gênero ao invés de ajudar a resolvê-la. Isto porque o modelo-padrão ensinado aos alunos de graduação estaria sub-repticiamente a promover a desigualdade de gêneros.

Para exemplificar essa influência, Castaño (1999) refere um modelo de economia simples, que explica a decisão de a mulher assumir a maior parte das responsabilidades de assistência à infância com base nas suas preferências entre trabalho doméstico e trabalho remunerado. A teoria econômica neoclássica abstrai o trabalho doméstico de sua estrutura social e política e analisa a família como se fosse uma pequena empresa que produz bens utilizando trabalho e insumos de mercado. Mais: supõe a vigência de um processo de substituição perfeita e automática entre tempo de trabalho doméstico e serviços oferecidos no mercado, partindo do pressuposto que as mulheres escolhem livremente entre ficar em casa ou trabalhar fora. De acordo com o preceito do homo oeconomicus, ao buscar maximizar a sua utilidade, as mulheres realizarão um cálculo de custos e benefícios entre o rendimento do trabalho doméstico não pago e o rendimento do trabalho de mercado pago. Já as economistas feministas, por sua vez, salientam que estas preferências supostamente atribuídas às mulheres têm sido formadas por uma sociedade patriarcal, machista e capitalista, com fortes pressões sociais e culturais acerca daquilo que as mulheres devam fazer, devam escolher, assim como dos papéis que elas devam desempenhar. Sendo assim, apresentar as escolhas feitas a posteriori como escolhas livres é de fato uma distorção. Tal modelo teórico, supostamente neutro e objetivo, ao não reconhecer o persistente potencial de discriminação contra as mulheres que atua, sub-repticiamente, por intermédio de seus conceitos e do seu método privilegiado de investigação, pode permitir que o sexismo passe em branco, argumentam.

Historicamente, a interface entre os estudos de gênero e a economia é um dos mais recentes programas de pesquisa em ciência econômica. Apenas em 1990 a conferência anual da American Economic Association pela primeira vez incluiu um painel específico voltado às perspectivas feministas na economia. Uma seleção dos artigos apresentados naquela altura foi publicada por Marianne Ferber e Julie Nelson posteriormente, em 1993, numa coletânea intitulada Beyond Economic Man: Feminist Theory and Economics. Com a publicação da série de livros e artigos que se seguiram às primeiras conferências, a economia feminista começou a tomar corpo como um campo organizado do conhecimento no início da década de 1990. Desde então, o processo de consolidação dessa abordagem vem-se desenvolvendo rapidamente, predominantemente nos Estados Unidos (mas também na Europa),

\footnotetext{
${ }^{5}$ Nomeadamente Elinor Ostrom, cientista política e economista norte-americana que em 2009 foi laureada com o prêmio de ciências econômicas em memória de Alfred Nobel juntamente com Oliver Williamson.
} 
em especial após a criação, em 1992, da International Association For Feminist Economics (IAFFE): espaço de debate entre os diversos enfoques possíveis da economia feminista, que passou a publicar em 1995 a primeira revista voltada para a discussão destas questões, intitulada Feminist Economics. O campo foi descrito pela primeira vez numa revista da Associação Americana de Economia também em 1995 (Nelson, 1995), uma enciclopédia sobre a economia feminista foi publicada em 1999 (Peterson e Lewis, 1999) e um livro sobre os resultados das discussões levadas a cabo nos primeiros 10 anos do estudo do feminismo na economia foi publicado em 2003 (Ferber e Nelson, 2003).

Uma crítica recorrente em vários destes trabalhos é a de que não existe uma perspectiva teórica econômica que possa ser universalmente válida, nem um modelo de comportamento econômico que possa ser indiscriminadamente aplicado para qualquer contexto, em qualquer país, em qualquer momento histórico, mesmo que esse momento seja adstrito ao capitalismo enquanto sistema de produção e reprodução social. Do mesmo modo, como não existe um varão homo oeconomicus, tampouco se poderia pensar em definir uma "mulher econômica", representante do gênero feminino e da sua condição no mundo da economia. Os condicionantes de gênero se combinam com os de raça, nacionalidade, classe social, nível de estudos, número de filhos, bem como com inúmeros outros fatores para determinar as circunstâncias laborais reais e as condições econômicas com as quais se deparam as mulheres, posicionamento este já igualmente proposto por vários teóricos das ciências sociais e da psicologia social, dentre os quais Collins (2000), Creenshaw (2000), Guimarães (2008) e Stolke (2006). Desta perspectiva, os problemas que enfrentam as mulheres no mercado de trabalho não são meramente "falhas de mercado", como pretendem os adeptos do mainstream da economia, mas sim constituem vieses resultantes da própria estrutura do sistema econômico e social de caráter classista, patriarcal, sexista e, não raro, étnico-racialmente discriminatório.

Desde a sua configuração enquanto área de investigação, a economia feminista vem desenvolvendo diversas linhas de pesquisa que exploram questões que, muito embora compartilhem várias propostas com outras correntes da economia heterodoxa, possuem características também muito próprias. Uma delas é a insistência no enfoque consoante o qual há uma interdependência entre as esferas da produção (âmbito do mercado) e da reprodução social (âmbito doméstico), tema este que será abordado na seção abaixo.

\section{TRABALHO DOMÉSTICO NÃO REMUNERADO/ TRABALHO NÃO PAGO/TRABALHO INVISÍVEL}

A economia tradicional estabelece uma separação bastante nítida entre o tempo de trabalho e o tempo de não trabalho, considerando o primeiro trabalho produtivo e o segundo trabalho improdutivo. "Trabalho produtivo" refere-se às tarefas produtivas que possuem valor de troca, ou seja, que são remuneradas no mercado. O resto do tempo, seja ele dedicado a alguma forma de trabalho não remunerado, 
ao ócio ou ao lazer, ou às atividades de higiene e cuidados pessoais ou familiares, é considerado como "não trabalho" ou "trabalho improdutivo" do ponto de vista econômico, tido como secundário e/ou marginal e, por isso mesmo, subordinado ao primeiro.

Uma parte importante desse tempo de não trabalho é dedicada à satisfação de algumas necessidades essenciais para o indivíduo, tais como dormir, vestir-se, lavar-se, alimentar-se, deslocar-se de um lugar para outro, etc. O restante do tempo pode ser efetivamente dedicado ao ócio (ou ao lazer) ou pode, ao contrário, ser dedicado aos cuidados com a casa e a família, às crianças, aos enfermos e/ou aos idosos que necessitem de atenção diária. Estes dois últimos tipos denomina-se, respectivamente, "trabalho doméstico" e "trabalho de cuidados" (caring labour).

Do ponto de vista econômico, as dificuldades envolvidas na mensuração do trabalho doméstico e de cuidados são enormes, e isso no que respeita tanto à sua qualidade, como à sua quantidade, assim como à sua produtividade. Normalmente, para a estimativa da produção não mercantil têm sido utilizadas duas técnicas alternativas: a primeira delas é realizada a partir dos inputs ou do tempo necessário para a realização das tarefas que não recebem contrapartida financeira. Trata-se, neste caso, de estimar a quantidade de horas de trabalho realizado em casa para com isso aferir o seu valor. Alternativamente, também é possível tentar estimar já os outputs, ou o preço que seria pago no mercado formal dos bens produzidos e dos serviços realizados em casa, a fim de aferir a magnitude da produção não mercantil para fins de um cálculo mais acurado e realista do PIB, por exemplo. O problema é que o caráter fragmentado, intermitente, imediato e pessoal do trabalho doméstico torna a mulher que o desempenha uma mistura de cozinheira, faxineira, arrumadeira, lavadeira, passadeira, babá, motorista e governanta, por assim dizer. Conseguir comprar no mercado todos estes serviços por pequenos períodos de tempo e em horários tão aleatórios quanto aqueles em que estes serviços são realizados ao longo de um dia de trabalho doméstico é uma tarefa que nem sempre é simples. Além disso, tem-se ainda a questão da sua baixa produtividade, muito em função de que, amiúde, a mulher está empenhada em realizar muitas dessas tarefas simultaneamente. Isso dificulta e muito a tarefa de imputação de um valor realista a tais serviços. Em termos técnicos, diz-se que o trabalho doméstico e os bens e serviços encontráveis no mercado não são substitutos perfeitos.

Como a economia não "enxerga" o trabalho doméstico, diz-se que ele é "invisível”. Essa metáfora é bastante significativa, levando-se em consideração que aquilo que não se vê parece de fato não existir... O problema é que esse trabalho, invisível do ponto de vista econômico, e por isso mesmo desvalorizado, além de repetitivo e exaustivo, é imperativo e iminente (amamentar e trocar as fraldas de um bebê, por exemplo), cotidiano (cozinhar, limpar e arrumar a casa, lavar a louça, tratar da roupa) e, além disso, consome muito tempo de cada dia, de todos os dias.

Tradicionalmente, tem-se estabelecido a divisão sexual do trabalho, com o homem assumindo o sustento e a reprodução econômica da família, encarregando-se do trabalho público, economicamente remunerado, produtivo, ao passo que à mulher caberia a reprodução física e as tarefas domésticas, que são o trabalho 
privado e não remunerado. A prática continuada desta divisão sexual do trabalho acabou por naturalizá-la e assumi-la em consonância com as respectivas funções masculina e feminina. Procurava-se assim evidenciar que a opção da mulher pelos trabalhos domésticos e dos cuidados familiares seria mais racional e adequada. Se a mulher optasse por ter uma vida profissional, desempenhando (também) uma ocupação remunerada, precisaria reduzir o seu tempo de lazer, uma vez que as tarefas domésticas continuariam a ser de sua responsabilidade. O que está por trás desta necessidade é a concepção segundo a qual não existiria a opção de se renunciar àquilo que se supõe que seja obrigação exclusiva de alguém.

Importa entretanto sinalizar que não coube apenas aos economistas clássicos a assunção destes pressupostos, mas foram igualmente alguns cientistas sociais, nomeadamente sociólogos como Parsons (1956) que, de modo mais elaborado, justificaram a referida divisão sexual do trabalho entre homem/marido e mulher/ esposa. Enquanto ao homem caberia o exercício da função instrumental de provedor da casa e ganha-pão da família, à mulher caberia a função expressiva enquanto cuidadora da casa, dos filhos e do próprio marido, com a correlativa distribuição de afetos e emoções aos membros da casa.

Embora desde os anos 1980 lentamente já se comece a perceber alguma mudança neste cenário, especialmente no Ocidente e no contexto das gerações mais jovens, as situações acima descritas ainda provocam efeitos nefastos sobre as mulheres do ponto de vista da igualdade de oportunidades e da possibilidade de acesso ao emprego, assim como do exercício de uma atividade profissional. Também repercutem negativamente sobre as suas respectivas carreiras, quando as mulheres conseguem aceder a tal. A pressão das obrigações domésticas determina que uma considerável parcela das mulheres aceite aquele tipo de emprego precarizado (em tempo parcial, informal, pior remunerado) que permita compatibilizar ambas as atividades, fora e dentro de casa, ao invés de desenvolver plenamente as suas aptidões em alguma atividade profissional.

Ao lançar luz sobre as condicionantes e as características do trabalho invisível, não remunerado, as análises da economia feminista têm pretendido explicitar, por um lado, quão importantes são as mulheres que o executam para a provisão de bem-estar de suas famílias e, portanto, por extrapolação, para o bem-estar social. Por outro lado, também colocam a descoberto quão deletérias são as consequências da dedicação ao trabalho não remunerado, especialmente em termos de perda de autonomia dessas mulheres, da escassez de tempo livre que essa circunstância acarreta e da falta de acesso a direitos sociais que normalmente acompanham as mulheres a ele submetidas (Bonetti e Abreu, 2011).

Sob o olhar da perspectiva feminista, há dois fenômenos associados ao trabalho invisível. $\mathrm{O}$ primeiro diz respeito às desigualdades de salários entre homens e mulheres com igual formação e que desempenham funções idênticas ou muito semelhantes, e o segundo refere-se à discriminação sob a forma de segregação - seja ela horizontal ou vertical - por gênero no mercado de trabalho, temas estes que serão abordados na sequência. 


\section{GÊNERO E DESIGUALDADE DE SALÁRIOS}

Com a incorporação crescente das mulheres em empregos fabris em substituição aos homens nos períodos das duas guerras mundiais do século passado, começaram a sobressair as diferenças salariais por gênero para empregos e ocupações idênticas ou muito similares. Este era um fenômeno totalmente não previsto pela teoria econômica neoclássica. Como é sabido, segundo os seus pressupostos, o mercado de trabalho é competitivo e o salário de equilíbrio seria aquele obtido na interseção entre as curvas de oferta e demanda de trabalho. Em termos abstratos, a teoria supõe uma tendência ao equilíbrio de todos os mercados, inclusive no de trabalho. No entanto, para que o equilíbrio no mercado de trabalho se desse, seria necessário que não houvesse nem a obrigação de realização de tarefas domésticas, que consistem em restrições pelo lado da oferta de trabalho, e nem tampouco atitudes discriminatórias por parte dos empregadores - desta vez restrições pelo lado da demanda por trabalho. Se porventura existissem diferenças salariais entre trabalhadores de ambos os sexos que fossem igualmente produtivos, era de esperar que, com o passar do tempo, elas desaparecessem. Isto porque, sendo os empregadores agentes racionais, eles prefeririam contratar os trabalhadores mais baratos (no caso, as mulheres), o que faria com que a demanda por trabalho feminino aumentasse. Como consequência deste aumento de demanda, o seu nível salarial elevar-se-ia até o nível salarial dos homens. Sendo assim, segundo a perspectiva da economia neoclássica, o que explicaria as diferenças salarias, caso elas existissem, seriam as imperfeições ou as chamadas "falhas de mercado". A teoria do capital humano (Schultz, 1961; Becker, 1965 e 1985) vai além e explica as diferenças salariais entre homens e mulheres que desempenham funções idênticas por meio da suposição de que haveria diferenças de produtividade associadas a um investimento em capital humano menor, ao longo da vida, e isso por decisão das próprias mulheres. Segundo essa concepção, a divisão do trabalho em casa determina que a mulher dedique mais tempo do que o homem para a família. Possuindo vantagens comparativas na esfera doméstica, e antevendo uma vida laboral mais curta e difícil e descontínua (em decorrência das gestações, dos anos de criação dos filhos pequenos e dos cuidados domésticos), as mulheres possuiriam menos incentivos para investir seja em educação formal, orientada para o mercado, seja em formação específica para seus postos de trabalho; numa palavra, em capital humano. Isso reduziria a sua possibilidade de ganhos em termos salariais comparativamente aos ganhos dos seus concorrentes do sexo masculino, pois os empresários prefeririam contratar os trabalhadores mais bem qualificados para cada função, no caso, os homens.

Além disso, essa situação também geraria, segundo a teoria do capital humano, segregação ocupacional, já que as mulheres acabariam por escolher ocupações em que a necessidade de investimento em capital humano fossem menos importantes (ou seja, trabalhos menos qualificados e pior remunerados) e a evitar os empregos que, de partida, requisessem muita especialização e portanto grandes investimentos em formação específica.

Diferentemente daquilo que propõem a teoria tradicional neoclássica e a sua 
variante, a teoria do capital humano, os modelos explicativos de inspiração feminista baseiam-se na tese de que existe discriminação no mercado de trabalho, ou seja, consideram que as diferenças salariais por gênero exprimem um tratamento desigual e, portanto, injusto para com indivíduos iguais ou potencialmente iguais. As diferenças no valor do salário entre gêneros, em uma grande parte de ocupações, não tem causa biológica relacionada às diferenças nas habilidades ou na força física entre os sexos, mas possui sim um caráter social ainda hoje vigente na maior parte das sociedades, relacionado à atribuição das tarefas de sustento da família ao homem e de cuidados domésticos e reprodução da força de trabalho à mulher. Entre as causas determinantes das diferenças de remuneração entre os gêneros, destacam-se, portanto, para além do maior ou menor investimento prévio em capital humano, também a existência de diferenciais de compensação para tipos de trabalhos e a discriminação (Kon, 2002).

Foi somente a partir da década de sessenta que as questões de discriminação no mercado de trabalho por gênero e raça começaram a ser debatidas. Além disso, a ideia de que para além do lazer as atividades domésticas poderiam incluir o trabalho não remunerado também ganhou terreno. Muitas vezes, porém, a avaliação dos economistas daquela época sobre estas questões servia simplesmente para justificar os papéis sexuais tradicionais na família, a segregação das mulheres numa estreita faixa de ocupações pagas e os seus ganhos menores no mercado de trabalho. Não obstante estes primeiros trabalhos terem reconhecido a existência das mulheres no mundo econômico, não se pode dizer que tiveram um cariz feminista, tendo em vista que eles serviram antes para racionalizar e legitimar, ao invés de questionar a dependência financeira das mulheres, assim como a sua reduzida capacidade de ação e de escolha no mundo laboral.

Como acabamos de referir, os economistas neoclássicos argumentavam que os padrões então existentes resultavam de escolhas racionais, com variações entre homens e mulheres apenas devidos a diferenças presumivelmente inatas nos gostos e nas habilidades entre ambos os sexos, expressos em diferentes escolhas com relação ao maior ou menor investimento em capital humano. A explicação baseava-se na utilização do seguinte raciocínio: os menores ganhos das mulheres no mercado de trabalho eram explicados em função da sua especialização no trabalho doméstico. Inversamente, também as suas responsabilidades domésticas eram usadas para justificar os seus salários inferiores. No entanto, há pelo menos dois problemas envolvidos nesse tipo de raciocínio: em primeiro lugar, há a questão da circularidade do argumento. Depois, como consequência disso, tampouco se consegue determinar a direção da causalidade: não se sabe se são as menores possibilidades de ganhos no mercado de trabalho a causa para que as mulheres invistam menos em capital humano ou se os seus salários mais baixos são o resultado de seus menores investimentos em formação (Castaño, 1999).

Por estes motivos, as justificativas que oferecem tanto a teoria neoclássica tradicional quanto a tese do capital humano para as diferenças salariais entre homens e mulheres têm sido especialmente criticadas pela abordagem feminista. Mas para além da questão dos salários desiguais para trabalhos iguais, existe um im- 
portante problema correlato que será abordado na sequência: a segregação do mercado de trabalho por gênero.

\section{GÊNERO E SEGREGAÇÃO/DISCRIMINAÇÃO NO MERCADO DE TRABALHO}

Há ocupações que são costumeiramente avaliadas como adequadas para as mulheres: secretária, enfermeira, recepcionista, cuidadora de idosos, professora infantil e babá, por exemplo. Já outras, ainda nos dias de hoje amiúde são percebidas como inadequadas, nomeadamente: neurocirurgiã, mecânica de automóveis, CEO de empresa multinacional ou piloto de caça, para mencionar apenas um número reduzido de casos. Por um lado, existe preconceito nesse tipo de clichê. Ele revela a crença segundo a qual as mulheres não são substitutas perfeitas dos homens e isso se deveria aos mais variados motivos: seja porque são consideradas menos confiáveis, seja porque seriam menos capazes, ou ainda menos produtivas ou menos estáveis do que eles. Por outro lado, estes preconceitos são reforçados por conta do vínculo das mulheres com o trabalho doméstico: os empresários não desejam empregar mulheres em cargos que exigem muita responsabilidade, pois pensam que elas durarão menos nos seus postos de trabalho do que os homens. Por outro, mesmo nos casos em que elas possuam o mesmo nível de formação que os homens, isto é, quando investiram tanto em capital humano quanto eles, as suas responsabilidades domésticas podem afetar (e de fato afetam) negativamente a sua capacidade de trabalho e, consequentemente, os seus salários. Isto porque o trabalho doméstico requer muito mais esforço do que o ócio (ou do que o lazer), como é óbvio. Isto posto, as mulheres casadas, estando mais cansadas do que os seus maridos dada a dupla jornada de trabalho que precisam enfrentar, supostamente se esforçarão menos do que os homens casados em cada hora de trabalho extradoméstico.

A segregação ocupacional por gênero refere-se à forma como as mulheres se distribuem entre as categorias laborais em comparação com os homens, já que, como referimos, não é incomum que as ocupações estejam estereotipadas como masculinas ou femininas. A segregação pode ser horizontal ou vertical: chama-se de segregação horizontal quando mulheres e homens trabalham majoritariamente em ocupações diferentes, como nos exemplos apresentados atrás. Além disso, também é possível identificar segregação por gênero por setores econômicos. Tradicionalmente, as mulheres tem se concentrado no setor terciário, de serviços, já que tendem a reproduzir, no espaço público, os mesmos tipos de trabalho, de cuidado e de educação que desempenham no espaço privado do lar.

Já a segregação vertical tem lugar quando a maioria dos trabalhadores que ocupam os postos mais elevados de determinada profissão é formada por homens, ao passo que a maioria dos trabalhadores que ocupam os escalões mais baixos é composta por mulheres.

Como regra geral, em todos os ramos profissionais, observa-se que, à medida 
que se ascende na escala profissional, aumenta a presença masculina independentemente do ramo de atividade em questão. Inversamente, à medida que se descende e se observam os escalões inferiores, percebe-se um aumento na quantidade de mulheres ocupando os postos de trabalho menos valorizados e remunerados das diversas profissões.

O conceito de segregação ocupacional por gênero é muito importante para explicar as diferenças salariais entre homens e mulheres, a concentração das mulheres em empregos secundários, menos qualificados, pior pagos, nos setores produtivos mais atrasados, com especializações obsoletas, enfim, a sua posição de subordinação no mercado de trabalho. As mulheres são a mão de obra preferencial em muitos empregos e ocupações. E como o universo laboral preferencial das mulheres é limitado a determinadas ocupações bem específicas, há uma grande procura por parte delas para uma oferta pequena de empregos nesses setores, o que faz com que o nível dos salários caia. Mas a desigualdade não se deve somente a isso, como acima referido: deve-se também ao fato de as mulheres serem as responsáveis pelo cuidado da casa e dos filhos, ou seja, à dupla jornada de trabalho.

Muito embora a participação feminina tenha começado a aumentar em empregos anteriormente reservados aos varões, a sua presença também se reforçou no setor e nas ocupações tradicionalmente femininas. Como dito, as mulheres concentram-se no setor terciário (setor de serviços), desempenhando hoje em dia praticamente as mesmas tarefas e ocupando via de regra as mesmas profissões alegadamente femininas, os empregos de cuidados (serviços pessoais e enfermagem), que as suas antececessoras ocupavam. Já as ocupações tipicamente masculinas, por outro lado, são mais variadas e dinâmicas, localizando-se sobretudo - porém não exclusivamente - nos setores primário e secundário da economia (agricultura e indústria $\left.{ }^{6}\right)$. Além disso, como referido, os homens também têm maior peso nas esferas de comando, chefia, gerência, diretoria e presidência das empresas, e isso em todos os setores econômicos, inclusive no terciário. A segregação por gênero também se dá em relação aos processos de trabalho como, por exemplo, os contratos a tempo parcial, que só assumem vulto e expressão no setor terciário e nas ocupações tipicamente consideradas como femininas.

Desigualdades de gênero no trabalho e na renda encontram-se em praticamente todos os países do mundo, ainda que com variados graus de intensidade no que se refere às dimensões étnico-raciais, geracionais e regionais. Dadas estas disparidades, as diferenças de renda entre os homens e as mulheres - vale dizer, aquilo a que se convencionou chamar de "distância de renda de gênero" - vêm despertando um grande esforço teórico de investigação e interpretação tanto na literatura econômica quanto na sociológica (Blau, Ferber e Winkler, 1998; Kon, 2002).

Para além disso, estudos comparativos internacionais conduzidos por Wright (1994, 1997), por exemplo, defendem a tese de que há um reforço mútuo entre as formas de desigualdade de classe e aquelas baseadas em fatores como gênero e

\footnotetext{
${ }^{6} \mathrm{Na}$ indústria, a participação feminina é representativa nos setores mais tradicionais: vestuário e têxtil.
} 
raça ${ }^{7}$. Encontrou-se respaldo empírico para a tese de que, enquanto força de trabalho, a mulher é mais proletarizada que o homem, há uma significativa desigualdade de gênero relativa à autoridade no local de trabalho; negros, em geral, são significativamente mais proletarizados que brancos; e as mulheres negras, em específico, são o grupo social mais proletarizado.

No gráfico apresentado abaixo (IPEA, 2016, p. 14) vemos exatamente este cenário espelhado no cenário brasileiro.

Rendimento médio do trabalho principal da população ocupada de 16 anos ou mais por sexo, raça /cor - Brasil, 2004 a 2014

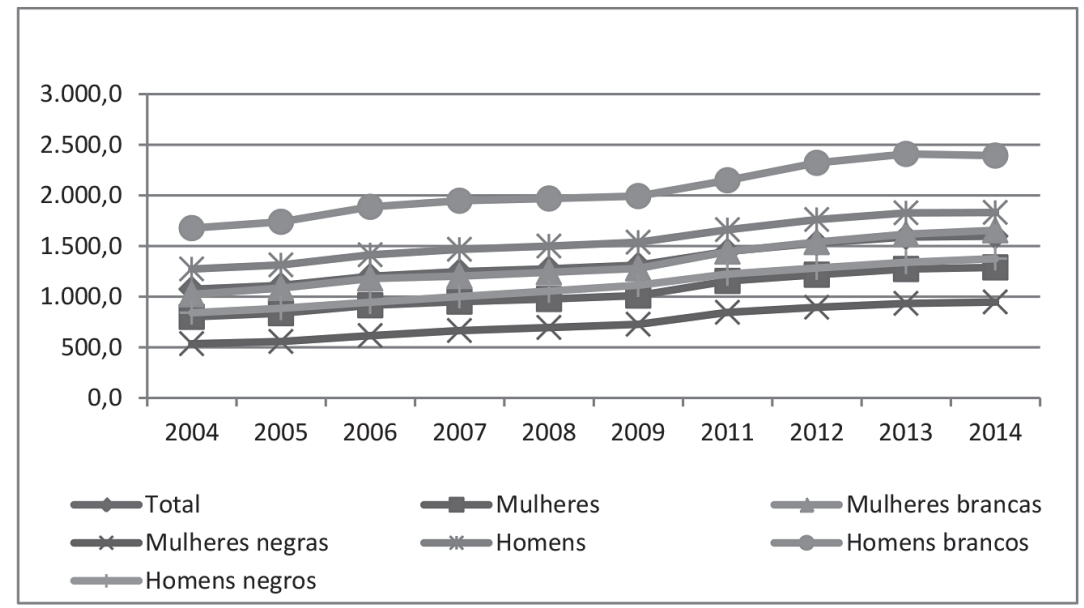

Fonte: Pnad/IBGE. Elaboração IPEA/DISOC/NINSOC - Núcleo de Gestão em Informações Sociais.

Neste resultado empírico recente conduzido a partir de dados (de 2004 a 2014) das Pesquisas Nacionais por Amostra de Domicílios (Pnad) feita pelo Instituto Brasileiro de Geografia e Estatística (IBGE) e elaborado pelo Instituto de Pesquisas Econômica Aplicada (IPEA, 2016) vemos corroborado o mesmo diagnóstico de subjugação das mulheres no mundo laboral que Wright $(1994,1997)$ identificou para o cenário mundial.

Como se observa, no Brasil, a renda média dos homens brancos é superior à renda média dos homens negros, que por sua vez é praticamente idêntica à renda média das mulheres brancas, que é superior à renda média das mulheres negras.

Nos estudos que visam colocar a descoberto as inter-relações entre desigualdades de gênero, raça e classe, parte-se do princípio de que a desigualdade de

\footnotetext{
${ }^{7}$ Não obstante, alguns resultados paradoxais também puderam ser observados nas análises empíricas de Wright: nos Estados Unidos, onde existe maior disparidade entre classes sociais, a diferença de gênero em autoridade no local de trabalho é menor, se comparada aos países nórdicos, por exemplo, onde existe menor desigualdade de classes. Além disso, independentemente da composição da classe do domicílio, maridos realizam poucas horas de trabalho doméstico em comparação com as mulheres, mesmo nos países desenvolvidos.
} 
classe traduz-se também em outras formas de desigualdade - como na (im)possibilidade de acesso à educação de qualidade, por exemplo - ao serem comparados países situados em níveis de desenvolvimento capitalista semelhantes, tem-se que, quanto mais desiguais as relações de classe dentro do capitalismo, mais desiguais as demais formas de divisão social de trabalho. Um passo além, seguindo essa linha de raciocínio, equivale a dizer que o estudo da desigualdade de gênero, à luz da desigualdade de classe, propicia outra forma importante de introduzir a questão mais geral da estrutura da desigualdade econômica dos países.

Este é um dos motivos pelos quais, no caso brasileiro, em que prevalece um contexto de elevada desigualdade de classe, alguns pesquisadores defendem que não seria adequado focalizar apenas os gaps de oportunidades associados às questões de discriminação por gênero, sem que se considerasse simultaneamente a estrutura da desigualdade econômica.

Outro tópico transversal que tem recebido muita atenção no contexto da situação específica da mulher no mundo econômico é aquele relacionado aos diversos aspectos da interseção entre gênero, macroeconomia e neoliberalismo, a serem apresentados na seção a seguir.

\section{GÊNERO, POLÍTICAS MACROECONÔMICAS VOLTADAS PARA O DESENVOLVIMENTO, E O NEOLIBERALISMO}

Quando se trata de políticas macroeconômicas, economistas feministas pensam que a igualdade de gênero seja valiosa por si só, e não apenas como um meio de promoção do crescimento econômico. Por outro lado, também consideram que as políticas públicas provocam efeitos diferenciados sobre homens e mulheres. Quando os serviços públicos são cortados, uma perspectiva da economista feminista salienta que aqueles indivíduos com maior probabilidade de preencher a lacuna deixada pelo Estado são as mulheres. Outra, de viés mais marxista, indica que os cortes nos serviços públicos se sustentam apenas porque existe o trabalho não remunerado das mulheres. Em decorrência de qualquer uma das razões apontadas, o fato digno de nota é que os cortes nos gastos públicos podem piorar ainda mais a já existente desigualdade de gênero.

As políticas de redução de gastos públicos com ênfase na austeridade fiscal, típicas dos ajustes econômicos de cariz neoliberal, possuem dimensões de gênero. Estas se exprimem em custos que recaem majoritariamente sobre as muheres. Estes custos, por sua vez, traduzem-se no aumento do desemprego entre as mulheres, no aumento do trabalho informal, na intensificação do trabalho doméstico, bem como na retirada de crianças (especialmente meninas) da escola a fim de aumentar o tempo necessário para a realização de serviços domésticos. Além disso, há outros custos de caráter menos facilmente identificáveis como decorrentes de questões econômicas, como o aumento do estresse na família e, consequentemente, da violência doméstica, por exemplo.

Em geral, os estudos voltados para as consequências das políticas econômicas 
de corte neoliberal mostram que os programas de ajustes macroeconômicos afetam mais intensamente as mulheres, no sentido de que modificam as relações entre as esferas produtivas e reprodutivas, transferindo para as famílias maior responsabilidade pela sobrevivência familiar. Haveria portanto nestes casos uma intensa transferência de responsabilidades do Estado para as famílias, sendo que o custo de se restabelecer o equilíbrio recai na habilidade das mulheres para desenvolver estratégias que permitam a sobrevivência da família com menos renda e mais trabalho (Rocha, 2005).

Outro dos temas relevantes tratados no contexto da macroeconomia a partir da ótica da economia feminista diz respeito aos diversos aspectos relacionados ao desenvolvimento econômico. Uma conclusão que emerge da tentativa de se definir desenvolvimento é a de que, enquanto processo multidimensional, ele engloba dimensões econômicas, sociais, políticas e culturais em sentido amplo - muitas das quais variáveis qualitativas que não raro envolvem dificuldades de mensuração -, não devendo ser confundido, portanto, com o mero crescimento econômico - variável estritamente quantitativa. Por exemplo, é possível conceber uma situação na qual um país tivesse experimentado crescimento em seu PIB médio per capita enquanto, simultaneamente, a desigualdade de renda tivesse aumentado. Uma situação desse tipo poderia ser classificada como crescimento econômico sem desenvolvimento. Inversamente, poder-se-ia identificar uma situação de desenvolvimento com crescimento negativo. Isto poderia ocorrer, por exemplo, caso importantes reestruturações tivessem sido realizadas nas relações de produção ou nas instituições políticas de um país, de modo a criar as condições para um desenvolvimento ulterior, embora a um custo de curto prazo representado por reduções do PIB em razão da desagregação dos sistemas de produção e distribuição então existentes. Ainda uma terceira situação, emblemática para a questão do trabalho doméstico não remunerado, foi capturada por uma espécie de anedota de economistas. Trata-se da situação na qual um homem casa-se com a sua empregada doméstica. Do ponto de vista factual, nada mudou, pois a mesma mulher continuará a executar as mesmas tarefas de antes. No entanto, do ponto de vista econômico, o PIB do país diminuiu, tendo em vista que um(a) trabalhador(a) assalariado(a) deixou de existir e um serviço deixou de ser vendido no mercado. $\mathrm{O}$ trabalho não remunerado é composto por toda uma gama de atividades que geram riqueza e que garantem a reprodução social do sistema. Ignorá-lo cria distorções quanto à avaliação da capacidade produtiva real de um país e reforça a indiferença para com aqueles que o executam, mulheres na sua maioria.

O cálculo da produção nacional ou Produto Interno Bruto é baseado numa metodologia que contabiliza majoritariamente bens e serviços monetariamente trocados no mercado formal ${ }^{8}$, deixando de fora o trabalho doméstico assim como

\footnotetext{
${ }^{8}$ Há alguns tipos importantes de bens e serviços não trocados no mercado, porém incluídos no cômputo do PIB - como os fornecidos gratuitamente pelo Estado à população a título de direitos sociais (a educação, saúde, etc.), os correspondentes ao aluguel de moradia, quando o morador é o proprietário,
} 
todo tipo de trabalho voluntário e informal, com todas as distorções que essas ausências geram, em especial no caso dos países em que tanto o trabalho doméstico quanto o trabalho informal possuem um peso significativo, como ocorre no Brasil. Sendo assim, o PIB exclui uma classe de atores que é em grande parte composta por mulheres. Os defensores da economia feminista lutam também por esta mudança. Muito embora o cálculo oficial do PIB ainda não inclua nenhuma forma de trabalho não remunerado, cada vez mais as agências internacionais como a Organização das Nações Unidas fazem o grau de bem-estar depender de medidas mais amplas de progresso do que aquelas que dependem exclusivamente da renda em dinheiro, tais como saúde, educação e longevidade. Esta, apesar de ainda não ser uma vitória completa, indica que a medição do desenvolvimento econômico começa a incorporar também as críticas a ela dirigidas pela economia feminista.

\section{CONSIDERAÇÕES FINAIS}

Vimos que a teoria econômica tradicional estabelece uma separação bastante rígida entre tempo de trabalho e tempo de não trabalho, vale dizer, entre o tempo dedicado ao trabalho no mercado formal, que possui valor de troca e por isso recebe uma contrapartida financeira, e aquele tempo dedicado seja aos cuidados pessoais, da casa, da família ou ao ócio e ao lazer. Com relação a estes dois últimos, ao não estabelecer qualquer distinção entre trabalho doméstico e de cuidados, por um lado, e ócio e lazer, por outro, a teoria entende que ambos deveriam igualmente ser considerados como "não trabalho", uma vez que não possuem valor de troca. De partida, considerar que o ócio e o trabalho doméstico pertençam à mesma categoria de "não trabalho", por si só, já constitui uma forma de cegueira da teoria tradicional diante de uma carga laboral que recai predominantemente sobre os ombros das mulheres. Ou seja, considerar o mercado como o local privilegiado para se definir o que será considerado como "econômico" provoca uma subvalorização das atividades (também) econômicas realizadas predominantemente por mulheres.

Dado este cenário, e seguindo para além da crítica ao paradigma dominante, seja em relação aos seus aspectos metodológicos, seja no que concerne os seus enfoques teóricos, o aporte da economia feminista busca tornar visível a contribuição das mulheres para a economia. São pesquisas que consideram o trabalho de forma mais ampla, incluindo o trabalho informal, o trabalho doméstico não remunerado (o assim chamado trabalho invisível), a divisão sexual do trabalho na família, buscando integrar a reprodução como fundamental à nossa existência. Além disso, em relação à produção de riqueza na sociedade, lutam pela incorporação da saúde, da educação e dos cuidados como aspectos relevantes e temas legítimos para a economia. Intimamente relacionada com a identificação teórica das questões

os produtos da agricultura de subsistência, e outros. A precificação desses bens é feita por meio de imputações (Lequiller e Blades, 2014). 
relevantes está a necessidade de revisão dos preceitos e conceitos da economia ortodoxa à luz das críticas da economia feminista e do princípio ético e moral da igualdade de gênero, considerando as esferas produtiva e reprodutiva e as relações existentes dentro delas e entre elas.

Pelas diversas razões teóricas elencadas ao longo do texto, corroboradas por estudos empíricos, quer internacionais, quer nacionais, entendemos que uma das questões centrais aqui em jogo é a tomada de consciência de que não existe igualdade de condições no mercado de trabalho formal entre homens e mulheres. Ademais, uma questão correlata e muito importante é que, para além do trabalho formal, remunerado e criador de valor de troca, há muito trabalho sendo realizado, e há muita economia (no sentido lato de geração e troca de riqueza) acontecendo fora dos estreitos limites do mercado constituído. Como o paradigma econômico tradicional se tem mostrado incapaz de tratar de forma adequada esta realidade, parece ter se tornado claro que o avanço do conhecimento científico na área econômica, aos moldes tradicionais, é insuficiente para atingir o projeto de desenvolvimento com justiça e emancipação social, a partir da concepção de equidade de gênero, objetivo este para o qual as quase três décadas de existência da economia feminista vem lenta, porém continuamente, prestando a sua contribuição.

\section{REFERÊNCIAS BIBLIOGRÁFICAS}

BARROSO, C. (2004). Metas de desenvolvimento do milênio, educação e igualdade de gênero. Cadernos de Pesquisa, v. 34, n. 123, p. 573-582.

BECKER, G. (1965). “A Theory of the Allocation of Time.” The Economic Journal, v. 75, n. 299, p. 493-517.

BECKER, G. (1985). “Human Capital, Effort and the Sexual Division of Labour.” Journal of Labour Economics, v. 3, n. 1, p. 33-58.

BERGMANN, B. (1989). "Does the market for women's labor need fixing?", Journal of Economic Perspectives, v. 3, n. 1, p. 43-60.

BLAU, F.; FERBER, M. e WINKLER, A. (1998). The economics of women, men and work. Upper Saddle River: Prentice Hall.

CARRASCO, C. (2006). "Economia Feminista: una Apuesta por otra Economia”. In: VARA M. (Coord.). Estudios sobre Gênero y Economia. Madrid: Ed. Akal.

CASTAÑO, C. (1999). "Economia y Genero", Politica y Sociedad, n. 32, p. 23-42.

COLLINS, P. (2000). "Black feminist thought". In: LES BACK; SALOMON (orgs.) Theories of race and racism. Londres e Nova Iorque: Routledge, pp. 404-420.

CRENSHAW, K. (2000). "Race, reform and retrenchment. Transformation and legitimation in antidiscrimination law”. In: LES BACK e SALOMON (orgs.) Theories of race and racism. Londres $\mathrm{e}$ Nova Iorque: Routledge, pp. 549-560.

DANBY, C. (2004). “Toward a gendered Post Keynesianism”. Feminist Economics, v. 10, n. 3, p. 55-75.

EMAMI, Z. (1993). "Challenges facing social economics in the twenty-first century: A feminist perspective". Review of Social Economy, v. 52, n. 4, p. 416-25.

FERBER, M. A.; NELSON, J. A. (1993). Beyond economic man: feminist theory and economics. Chicago: University of Chicago Press.

FERBER, M. A.; NELSON, J. A. (2003). Feminist economics today. Beyond economic man. Chicago: University of Chicago Press. 
GUIMARÃES, A. (2008). “Cor e raça. Raça, cor e outros conceitos analíticos”. In: PINHO, I. e SANSONE, L. (orgs.) Raça. Novas perspectivas antropológicas. Salvador: ABA, UFBA, pp. 63-82.

HARDING, S. (1993). The science question in feminism. London: Cornell.

IPEA (2016). Mulheres e trabalho: breve análise do período 2004-2014. Nota técnica n² 24. Brasília. Disponível em: http://repositorio.ipea.gov.br/bitstream/11058/6524/1/Nota_n24_Mulheres_trabalho.pdf Acesso em 30/08/2017.

KON, A. (2002). "A economia política do gênero: determinantes da divisão do trabalho". Revista de Economia Política, v. 22, n. 3, p. 89-106.

KUIPER, E. e SAP, J. (1995): Out of the margin: feminist perspectives on economics. London: Routledge.

LACEY, H. (1999). Is Science Value Free? Values and Scientific Understanding. New York: Routledge, 1999.

LEQUILLER, F. e BLADES, D. (2014). Understanding national accounts. Paris: OECD, 2014,

LONGINO, H. (1993). "Subjects, power and knowledge: descriptions and prescriptions in feminist philosophies of science”. In: KELLER, F., LONGINO, H. (ed.) Feminism and Science. Oxford: Oxford University Press, p. 264-279.

NELSON, J. (2003). "Confronting the science/value split: notes on feminist economics, institutionalism, pragmatism and process thought". Cambridge Journal of Economics, v. 1, n. 27, p. 49-64.

NELSON, J. (1995). "Feminism and economics". The Journal of Economic Perspectives, v. 9, n. 2, 1995. p. 131-148.

PETERSON, J.; LEWIS, M. (1999). The Elgar Companion to Feminist Economics. Cheltenham: Edward Elgar.

PERKINS, P. (ed.) (1997). "Women, ecology and economics”. Special issue of Ecological Economics, v. 20, n. 2.

ROCHA, M. C. (2005). “As políticas neoliberais implementadas no Brasil nos anos 90 e as repercussões na vida das trabalhadoras”. Caderno Espaço Feminino, v. 14, n. 17, p. 125-142.

ROBEYNS, I. (2005). “A decade of feminist economics”. Journal of Economic Methodology, v.12, n. 4, p. 613-17.

SANTOS, J. A. (2008). “Classe social e desigualdade de gênero no Brasil, DADOS” - Revista de Ciências Sociais, v. 51, n. 2, p. $353-402$.

SCHULTZ, T. (1961): “Investment in Human Capital”, The American Economic Review, v. 51, n. 1, p. 1-17.

STAVEREN, I. (2008). "Post Keynesianism meets feminist economics". Cambridge Journal of Economics, v. 34, n. 6, p. 1123-44.

STOLKE, V. (2006). "O enigma das interseções: classe, raça, sexo, sexualidade. A formação dos imprérios transatlânticos do século XVI ao XIX”. Estudos Feministas, vol. 14, n. 1, pp. 15-42.

STROBER, H. (1994). "Rethinking economics through a feminist Lens". The American Economic Review, v. 84, n. 2, p. 143-147.

TILES, M. (1987). “A science of Mars or of Venus?” In: KELLER, F., LONGINO, H. (ed.) Feminism and Science. Oxford: Oxford University Press. p. 221-234.

WRIGHT, E. O. (1994). Interrogating inequality: essays on class analysis. London: Verso.

WRIGHT, E. O. (1997). Class counts: Comparative studies in class analysis. Cambridge: Cambridge University Press.

\section{ANEXO - SYLLABUS}

\section{Gênero e Economia: Aspectos filosóficos e metodológicos}

[1] BARKER, D.; KUIPER; E. (eds.) (2003). Toward a feminist philosophy of economics. London and New York: Routledge.

[2] FERNANDEZ, B. (2008): "Economia feminista: uma proposta epistemológica em defesa do pluralismo". In: $3^{\circ}$ Prêmio Construindo a Igualdade de Gêneros - redações e trabalhos científicos monográficos vencedores. Brasília: Presidência da República / Ministério da C\&T, p. 37-55. 
[3] NELSON, J. (1996) Feminism, objectivity, and economics. London: Routledge.

[4] NELSON, J. (2001). "Economic methodology and feminist critiques". Journal of Economic Methodology, v. 8, n. 1, p. 93-7.

[5] ROBEYNS, I; (2001). "Esiste una metodologia economica feminista?” In: Di CORI, P.; BARAZETTI, D. Gli studi della donna in Italia. Una guida crítica. Roma: Carrocci, p. 119-145.

II. Economia Feminista: enfoques, conceitos e propostas teóricas

[6] CARRASCO, C. (ed.) (1999). Mujeres y economía. Nuevas perspectivas para viejos e novos problemas. Barcelona: Icaria Editions.

[7] FARIAS, N.; NOBRE, M; (org) (2002). Economia Feminista. São Paulo: SOF.

[8] FERBER, M.; NELSON, J. (eds.) (1993). Beyond economic man: feminist theory and economics. Chicago: University of Chicago Press.

[9] FERBER, M.; NELSON, J. (eds.) (2003). Feminist economics today: beyond economic man. Chicago: University of Chicago Press.

[10] NELSON, J. (1995). "Feminism and economics". The Journal of Economic Perspectives, v. 9, n. 2, p. 131-48.

\section{Gênero e Desigualdade de Salários}

[11] BERIK, G., ROGERS, Y.; ZVEGLICH, J. (2004). "International trade and gender wage discrimination: Evidence from East Asia”. Review of Development Economics, v. 8, n. 2, p. 237-54.

[12] KLASEN, S.; LAMANNA, F. (2009). "The impact of gender inequality in education and employment on economic growth: new evidence for a panel of countries". Feminist Economics, v. 15, n. 3, p. 91-132.

[13] RUBERY, J. (Ed.) (1998). Equal pay in Europe? London: Macmillan.

[14] SCHOBER, T.; WINTER-EBMER, R. (2011). "Gender wage inequality and economic growth: is there really a puzzle? - a comment”. World Development, v. 39, n. 8, p. 1476-84.

[15] RANSOM, M.; OAXACA, R. (2010). "New market power models and sex differences in pay". Journal of Labor Economics, v. 28, n. 2, p. 267-89.

\section{Gênero e Segregação / Discriminação no Mercado de Trabalho}

[16] BERGMANN, Barbara (1974). "Occupational segregation, wages and profits when employers discriminate by race or sex". Eastern Economic Journal 1 (2/3), p. 103-10.

[17] BLAU, F.; FERBER, M.; WINKLER, A. (2010). "Differences in Occupations and Earnings: the role of labor market discrimination”. In: The economics of women, men, and work, $\mathrm{N} \mathrm{J}$ : Prentice Hall.

[18] DARITY, W.; MASON, P. (1998). "Evidence on discrimination in employment: codes of color, codes of gender". Journal of Economic Perspectives, v. 12, n. 2, p. 63-90.

[19] FIGART, D. (1997). "Gender as more than a dummy variable: Feminist approaches to discrimination”. Review of Social Economy, v. 55, n. 1, p. 1-32.

[20] HARTMAN, H. (1976). "Capitalism, patriarchy and job segregation by sex". Signs, v. 1, n. 3, p. 137-69.

\section{Trabalho Doméstico não Remunerado/Trabalho não Pago/Trabalho invisível}

[21] BARKER, D. (2005). “Beyond women and economics: rereading women’s work”. Signs, v. 30, n. 4, p. 2189-209.

[22] Feminist Economics, (1996) Special Issue on Unpaid Household Work (in honour of Margaret Reid), v. 2, n. 3.

[23] FOLBRE, Nancy (2006). "Measuring care: gender, empowerment, and the care economy”. Journal of human development, v. 7, n. 2, p. 183-99.

[24] MELO, H. P.; CONSIDERA, C.; SABBATO, A. (2007) "Economia e Sociedade: Os Afazeres domésticos contam". Economia e Sociedade, v. 16, n. 3, p. 435-54. 
[25] PAULILO, M. I. (2004). “Trabalho familiar: uma categoria esquecida de análise”. Revista Estudos Feministas, v. 12, n. 1, p. 229-52.

\section{Gênero, políticas macroeconômicas voltadas para o desenvolvimento e o neoliberalismo}

[26] ALVAREZ, S. (2014). "Neoliberalismos e as trajetórias dos feminismos latino-americanos". In: MORENO, Renata (Org.) Feminismo, economia e política: debates para a construção da igualdade e autonomia das mulheres. SOF: São Paulo, p. 23-8.

[27] BENERÍA, L. (2003). “Markets, globalization and gender”. In: Gender, development, and globalization: economics as if all people mattered. London and New York: Routledge, p. 63-90.

[28] LEON, M. (2003). "Uma visão feminista sobre a economia e a globalização". In: Ações das mulheres contra o jogo da OMC. São Paulo: SOF, REF, MMM.

[29] NELSON, J. (2005). "Rethinking development and globalization: insights from feminist economics". The Good Society, v. 14, n. 3, p. 58-62.

[30] STANDING, G. (1989). “Global feminization through flexible labor”. World development v. 17, n. 7, p. 1077-95.

\section{Economia Feminista e suas Interseções com outras Abordagens Heterodoxas}

[31] DANBY, C. (2004). “Toward a gendered Post Keynesianism”. Feminist Economics, v. 10, n. 3, p. 55-75.

[32] EMAMI, Z. (1993). "Challenges facing social economics in the twenty-first century: A feminist perspective". Review of Social Economy, v. 52, n. 4, p. 416-25.

[33] NELSON, J. (2003). "Confronting the science/value split: notes on feminist economics, institutionalism, pragmatism and process thought". Cambridge Journal of Economics, v. 1, n. 27, p. 49-64.

[34] PERKINS, P. (ed.) (1997). "Women, ecology and economics". Special issue of Ecological Economics, v. 20, n. 2.

[35] STAVEREN, I. (2008). "Post Keynesianism meets feminist economics". Cambridge Journal of Economics, v. 34, n. 6, p. 1123-44. 